\title{
Modernising public-health infrastructure
}

\author{
Stephen Corbett
}

Published online: 30 July 2009

(c) Birkhäuser Verlag, Basel/Switzerland 2009

Between 1348 and 1700, the states of Northern and Central Italy were among the earliest to establish health magistracies in major cities-Venice, Florence and Milan-to coordinate responses to recurring epidemics of bubonic plague. In the fifteenth century, these magistracies had become permanent and had turned their attention to the creation, oversight and maintenance of what we now might call a public health infrastructure (Public Health Infrastructure Resource Centre 2009); the quality of food and medicines, the movement of beggars and prostitutes, activities of doctors and hospitals, sanitary conditions in the poorest neighbourhoods, the quarantining of ships and the keeping of registers of mortality among many others (Cipolla 1992). One of the great achievements of British sanitary reform in the nineteenth century was to extend this tradition of governance of public health to include the built environment. Initially these reforms were focussed on a narrow set of hazards in rapidly expanding cities; local authorities were vested with responsibility for building standards and town planning, the control of noxious trades, water supply, sewage disposal, the management of burials and mortuaries and vermin control.

Stephen Corbett is a Public-Health physician and Director of the Centre for Population Health Sydney, West Area Health Service, and Associate Professor at the University of Sydney, School of Population Health and Western Clinical School.

S. Corbett $(\bowtie)$

School of Public Health, Western Clinical School,

University of Sydney, Gungurra (Building 68)

Cumberland Hospital, Locked Bag 7118,

Parramatta BC, NSW 2150, Australia

e-mail: Stephen_Corbett@wsahs.nsw.gov.au
Since then the public health infrastructure has evolved and expanded-shaped by population growth, technological innovation, community expectations, environmental and resource constraints and importantly the national and international experience of regulatory and system failure, and disaster. What have not kept pace with this expansion are the adaptations to the built environment necessary to address contemporary health concerns, particularly the prevention of chronic disease (Corbett 2008). In part, this may be due to the dispersion across government of custody of this infrastructure; public health professionals have less involvement in day-to-day risk management than environmental scientists, traffic engineers, building safety experts and professional urban planners (Perdue et al. 2003).

Dams, pipes, sewers, road surfacing and energy infrastructure represent only a part of the vast fixed investment for public health in the built environment. Of greater importance is the institutional capacity to effectively regulate hazards to health and to anticipate and avert system failure; public health laws which are aligned with contemporary public health problems; a workforce skilled and empowered to work across bureaucratic and professional boundaries, and an information infrastructure capable of continuous monitoring of hazards and health and regulatory effectiveness.

There is a strong justification for continued regulation of the built environment for public health (Perdue et al. 2003), and for a more explicit role for public health agencies and professionals in defining or redefining public health objectives so that they are both mindful of the need to maintain and improve what we have but are better aligned with the major causes of ill health and disability in the community (Corbett 2005).

For example, there is an urgent need for urban planners to be empowered to consider a much broader range of 
health impacts of urban planning, transport or building proposals. Often only small steps are required:

- Whilst pedestrian safety will be a normal inclusion in any development proposal, explicit consideration of extent to which a proposal encourages walking could easily be appended (Perdue et al. 2003).

- The obesity epidemic and its links to sedentary lifestyles and, perhaps to an urban form which predicates reductions in levels of physical activity has prompted policy proposals which would prescribe the location and number of fast food outlets and fresh food retailers, and mandate specified urban residential densities. A more promising approach may be an ongoing review of existing ordinances for pedestrian and cycling throughways, zoning, and lot size and layout. For example, in Sydney new developments make specific provision for the co-location of fuel and food outlets, a convention which embeds car dependence for even the shortest journeys.

What is needed to achieve this change? In an echo of the approaches taken by the sanitary reformers of the nineteenth century, I would suggest that first we need modern public health statutes, such as the Turning Point initiative (Turning Point Model State Public Health Act 2003) which facilitates institutional development and comprehensive regulatory responses to contemporary public health risks. Second, we need to train a cadre of appropriately trained professionals and develop communities of practice, particularly in relation to the intersection of urban planning and public health. Finally, for politicians and governments we need to demonstrate that modern public health regulation can be efficient and effective, often surprisingly popular and relatively free of red tape and the taint of overbearing government intervention in the lives of its citizens.

\section{References}

Cipolla C (1992) Miasmas and disease: public health and the environment in the pre-industrial age. Yale University Press, New Haven

Corbett S (2005) A ministry for the public's health: an imperative for disease prevention in the 21st century. Med J Aust 183:254-257

Corbett S (2008) Public health and regulation of the built environment. NSW Public Health Bull 19:212-215

Perdue WC, Gostin LO, Stone LA (2003) Public health and the built environment: historical, empirical and theoretical foundations for an expanded role. J Law Med Ethics 31:557-566

Public health infrastructure resource centre (2009) Accessed 27 March 2009 at http://www.phf.org/infrastructure/phfpage.php? page_id=20\#1

Turning point model state public health act (2003) Accessed 27 March 2009 at http://www.turningpointprogram.org/Pages/pdfs/ statute_mod/phsm_talking_points_TP_act.pdf 